\title{
nab-paclitaxel/carboplatin induction in squamous NSCLC: longitudinal quality of life while on chemotherapy
}

Michael Thomas, ${ }^{1,2}$ David R Spigel, ${ }^{3}$ Robert M Jotte, ${ }^{4}$ Michael McCleod, ${ }^{5}$ Mark A Socinski, ${ }^{6}$ Ray D Page, ${ }^{7}$ Laurent Gressot, ${ }^{8}$ Jeanna Knoble, ${ }^{9}$ Oscar Juan, ${ }^{10}$ Daniel Morgensztern, $"$ Dolores Isla, ${ }^{12}$ Edward S Kim, ${ }^{13}$ Howard West, ${ }^{14}$ Amy Ko, ${ }^{15}$ Teng Jin Ong, ${ }^{15}$ Nataliya Trunova, ${ }^{15}$ Cesare Gridelli, ${ }^{16}$

\section{On behalf of $A B O U N D . s q m$ investigators}

'Department of Thoracic Oncology/Internal Medicine, Thoraxklinik im Universitätsklinikum Heidelberg, ${ }^{2}$ Translational Lung Research Center Heidelberg, Heidelberg, Germany; ${ }^{3}$ Sarah Cannon Research Institute, Nashville, TN, ${ }^{4}$ Department of Medical Oncology/ Hematology, Rocky Mountain Cancer Centers, Denver, CO, ${ }^{5}$ Florida Cancer Specialists, Fort Myers, ${ }^{6}$ Florida Hospital Cancer Institute, Orlando, FL, ${ }^{7}$ The Center for Cancer and Blood Disorders, Fort Worth, ${ }^{8}$ North Cypress Cancer Center, Cypress, TX, ${ }^{9}$ The Mark H.

Zangmeister Center, Columbus, $\mathrm{OH}$, USA ${ }^{10}$ Department of Medical Oncology, Hospital Universitari i Politécnic La Fe, Valencia, Spain; "Department of Medical Oncology, Washington University School of Medicine in St. Louis, St. Louis, MO, USA; '2 Department of Medical Oncology, University Hospital Lozano Blesa, Zaragoza, Spain; ${ }^{13}$ Levine Cancer Institute, Carolinas HealthCare System, Charlotte, NC, ${ }^{14}$ Thoracic Oncology Program, Swedish Cancer Institute, Seattle, WA, ${ }^{15}$ Celgene Corporation, Summit, NJ, USA; ${ }^{16}$ Department of Oncology/Hematology, S.G. Moscati Hospital, Avellino, Italy

Correspondence: Michael Thomas Department of Thoracic Oncology/ Internal Medicine, Thoraxklinik/University of Heidelberg, Röntgenstraße I, D-69I26 Heidelberg, Germany

Tel +49622I 396 I30I

Fax +49622I $396 \quad 1302$

Email michael.thomas@med.uni-heidelberg.de
This article was published in the following Dove Press journal:

Lung Cancer:Targets and Therapy

30 October 2017

Number of times this article has been viewed

Background: Longitudinal data on the impact of treatment on quality of life (QoL) in advanced non-small cell lung cancer (NSCLC) are limited. In this palliative setting, treatment that does not deteriorate QoL is key. Here we report longitudinal QoL in patients with squamous NSCLC, receiving $\leq 4$ cycles of $n a b$-paclitaxel/carboplatin combination chemotherapy.

Methods: Patients received $n a b$-paclitaxel $100 \mathrm{mg} / \mathrm{m}^{2}$ days $1,8,15+$ carboplatin area under the curve $6 \mathrm{mg} \bullet \mathrm{min} / \mathrm{mL}$ day 1 (q3w) for four cycles. QoL was assessed by the Lung Cancer Symptom Scale (LCSS) and Euro-QoL-5 Dimensions-5 Levels (EQ-5D-5L) at baseline and each cycle (day 1).

Results: Two-hundred and six lesion-response-evaluable patients completed baseline $+\geq 1$ postbaseline QoL assessment and were QoL evaluable. LCSS average total score and symptom burden index improved from baseline throughout four cycles. In the LCSS pulmonary symptoms score, $46 \%$ of patients reported clinically meaningful improvement ( $\geq 10 \mathrm{~mm}$ visual analog scale) from baseline. Individual EQ-5D-5L dimensions remained stable/improved in $\geq 83 \%$ of patients; $\approx 33 \%$ reported complete resolution of baseline problems at least once during four cycles. Generally, responders (unconfirmed complete/partial response) had higher scores vs nonresponders. Conclusion: In patients with squamous NSCLC, four cycles of nab-paclitaxel/carboplatin demonstrated clinically meaningful QoL improvements, with greater benefits in responders vs nonresponders.

Keywords: $n a b$-paclitaxel, non-small cell lung cancer, quality of life, response, squamous

\section{Introduction}

Patients with advanced non-small cell lung cancer (NSCLC) often experience a high symptom burden and a significantly deteriorated quality of life (QoL). ${ }^{1-3}$ In a realworld cross-sectional analysis of patients receiving treatment for advanced NSCLC $(\mathrm{N}=450)$, all patients reported experiencing fatigue, and most experienced loss of appetite, shortness of breath, cough, hemoptysis, and pain. ${ }^{4}$ These data indicate that in addition to prolonging survival, identifying a first-line treatment regimen that does not deteriorate physical well-being but instead maintains or improves symptom burden and/or QoL, is important for disease and treatment outcomes.

Despite recent treatment advances, chemotherapy remains the first-line standard of care for the majority of patients with advanced NSCLC (without a high level of PD-L1 expression), including those with squamous histology. ${ }^{5,6}$ However, there is a paucity of longitudinal QoL data from patients with advanced NSCLC receiving chemotherapy, and the data that do exist are often contradictory. Some studies have found 
that platinum-based chemotherapy improves QoL, ${ }^{7}$ while others have found no improvement in QoL when compared with other treatments such as targeted agents. ${ }^{8-10}$ Prospective QoL data from clinical trials are even more limited in patients with squamous NSCLC, as few trials have reported QoL outcomes by histology.

$n a b$-Paclitaxel in combination with carboplatin is approved for the first-line treatment of locally advanced or metastatic NSCLC in patients who are not candidates for curative surgery or radiation therapy, based on a favorable risk-benefit profile compared with paclitaxel plus carboplatin in a randomized Phase III trial. ${ }^{11,12}$ Compared with paclitaxel plus carboplatin, nab-paclitaxel plus carboplatin demonstrated a significant increase in the primary endpoint of overall response rate (ORR) (33\% vs $25 \%, P=0.005)$ in the intent-to-treat population. A subset analysis of patients with squamous histology demonstrated a $68 \%$ improvement in ORR with nab-paclitaxel plus carboplatin compared with paclitaxel plus carboplatin $(41 \%$ vs $24 \% ; P<0.001) .{ }^{12}$ The $n a b$-paclitaxel plus carboplatin regimen was also well tolerated across histologies, as evidenced by the safety profile and patient-reported taxane-related symptom improvements. ${ }^{12-14}$ Although significant reductions in taxane-related symptoms such as neuropathy and neuropathic pain were reported with nab-paclitaxel plus carboplatin compared with paclitaxel plus carboplatin, it should be noted that improvements in these taxane-related symptoms may not reflect improvements in overall patient QoL. ${ }^{14}$ This further underscores the need to assess the impact of this regimen on QoL in a prospective clinical trial.

The Phase III ABOUND.sqm trial is investigating firstline $n a b$-paclitaxel plus carboplatin treatment followed by $n a b$-paclitaxel with or without best supportive care as maintenance treatment in patients with advanced squamous NSCLC. The objective of this analysis was to evaluate the impact of four cycles of $n a b$-paclitaxel plus carboplatin on patient-reported symptoms and health-related QoL outcomes.

\section{Ethics approval and consent to participate}

This study was conducted in accordance with the Declaration of Helsinki and Good Clinical Practice Guidelines of the International Conference on Harmonisation. Informed consent was obtained from all patients prior to study entry. The study received approval from institutional review boards prior to commencement. The trial is registered at ClinicalTrials.gov (NCT02027428).

The approving Institutional Review Boards/Ethics Committees were Bundesinstitut für Arzneimittel und Mediz- inprodukte, Ethikkommission der Medizinischen Fakultät Heidelberg, Agenzia Italiana del Farmaco, Comitato Etico Campania Nord, Agencia Española de Medicamentos y Productos Sanitarios (AEMPS), CEIC Hospital Clinico San Carlos, Health Research Authority, Medicines and Healthcare Products Regulatory Agency, NRES Committee London Surrey Borders, and Quorum Review IRB.

\section{Materials and methods Study population}

Patients with stage IIIB or IV, histologically or cytologically confirmed squamous NSCLC measurable by "Response Evaluation Criteria In Solid Tumors" (RECIST) version 1.1 were enrolled in this study. Key eligibility requirements included $\geq 18$ years of age, no prior chemotherapy for metastatic disease, Eastern Cooperative Oncology Group performance status of 0 or 1 , and adequate hematologic, renal, and liver function. Patients with active brain metastases or preexisting peripheral neuropathy grade $\geq 2$ were excluded.

\section{Study design}

The Phase III, randomized, open-label, multicenter ABOUND.sqm study is being conducted at $\approx 120$ sites in the United States and the European Union. In the induction part, patients were treated with $n a b$-paclitaxel (ABRAXANE ${ }^{\circledR}$, albumin-bound paclitaxel) $100 \mathrm{mg} / \mathrm{m}^{2}$ intravenously on days 1,8 , and 15 plus carboplatin area under the curve $6 \mathrm{mg} \cdot \mathrm{min} / \mathrm{mL}$ intravenously on day 1, every 21 days. After completion of four cycles, patients without progression could continue to the maintenance part of the study in which they would be randomized 2:1 to receive $n a b$-paclitaxel $100 \mathrm{mg} / \mathrm{m}^{2}$ intravenously on days 1 and 8 every 21 days plus best supportive care or best supportive care alone until disease progression. Randomization was stratified by disease stage before four cycles of treatment (IIIB vs IV), response at randomization (complete response/partial response [CR/PR] vs stable disease), and performance status at the end of the induction part ( 0 vs 1 ). The primary endpoint of the study is progression-free survival, which was measured from the time the patient was randomized at the start of the maintenance portion to the point of progression during the maintenance portion. Secondary endpoints include overall survival from randomization through the maintenance part, ORR during the induction and maintenance parts, and disease control rate over the entire study. Change in patient-reported QoL during the induction and maintenance parts was a prespecified exploratory endpoint. 


\section{QoL assessments}

The Lung Cancer Symptom Scale (LCSS) and the EuroQoL-5 Dimensions-5 Levels (EQ-5D-5L) questionnaires were used to measure QoL (Figure S1). In this analysis, per protocol, patient-reported QoL was assessed using the LCSS and EQ-5D-5L during four cycles of treatment on day 1 of each cycle through the end of the induction phase (cycle 5 day 1; prior to maintenance treatment). Patients completed the QoL self-assessments in the clinic using digital tablets.

The LCSS is a validated, disease-specific instrument completed by both patients and observers to measure QoL in patients with lung cancer. ${ }^{15}$ The patient version of the LCSS consists of eight individual questions about lung cancer symptoms (appetite, fatigue, dyspnea, cough, pain, hemoptysis, overall symptom severity, and normal activities) all measured during the past 24 hours, one global question on QoL, one average total score of the nine questions, and one mean score of the six questions on major lung cancer symptoms. Patients answer each question using a visual ana$\log$ scale (VAS) of 0 to $100 \mathrm{~mm}$, where $0=$ best and $100=$ worst to indicate the intensity of a symptom. Figure S1 shows the components of the LCSS scores used in this analysis.

The EQ-5D is a generic instrument designed for selfcompletion that measures the patient's health today and comprises the EQ-5D and a VAS for overall QoL. ${ }^{16,17}$ The EQ-5D includes questions on five dimensions of health (mobility, self-care, usual activities, pain/discomfort, and anxiety/depression). The answers to each EQ-5D-5L question are based on five qualitative levels (no problems, slight problems, moderate problems, severe problems, or unable to perform the activity). The EQ-5D-5L global index combines each of the five dimensions as a measure of the patient's global health state. The VAS records the patient's self-rated status for overall QoL based on a scale of 0 to 100 where $0=$ worst and $100=$ best.

\section{Lesion response evaluation}

Patients had a radiographic evaluation of lesions at the end of cycles 2 and 4. Patients with a CR or PR (by RECIST version 1.1 during the induction phase per the investigator), or those who experienced progressive disease in either evaluation or stable disease in both evaluations, or those who discontinued before or by the end of cycle 4 , were considered lesion-response-evaluable.

\section{Statistical analysis}

This analysis included patients who were lesion-responseevaluable during the induction part of the study with available
QoL data from baseline and $\geq 1$ postbaseline visit. A clinically meaningful improvement in LCSS or EQ-5D VAS-scaled questions was defined as $\geq 1$ postbaseline score for a given time point that was $\geq 10 \mathrm{~mm}$ higher than the baseline score. ${ }^{3}$ For statistical analysis purposes, all scales were aligned so that a positive change from baseline indicated improvement. Changes from baseline LCSS and EQ-5D VAS-scaled items were described by descriptive statistics. The percentages of patients who had a clinically meaningful response, of patients who maintained or improved from baseline in the 5 EQ-5D-5L dimensions, and of patients who had complete resolution of a baseline problem at least once during four cycles of treatment are summarized.

\section{Results \\ Patients}

Of the 540 patients planned for enrollment into the induction part of the study, 284 patients had been treated as of September 6, 2016. Of these 284 patients, 246 patients were lesion-response-evaluable. Of the lesion-response-evaluable patients, the median age was 68 years, and $41 \%$ of patients were aged $\geq 70$ years. The majority $(67 \%)$ of patients had a baseline Eastern Cooperative Oncology Group performance status of 1 (Table 1).

\section{QoL compliance}

Of the 284 patients treated in the induction part, 251 were treated in cycle $\geq 2$ and were eligible to complete $\geq 1$ postbaseline QoL assessment. Of these, 223 (89\%) completed baseline and $\geq 1$ postbaseline assessments.

\section{QoL results LCSS}

In total, 206 patients were lesion-response-evaluable with available QoL data from baseline and $\geq 1$ postbaseline visit and were included in the LCSS analysis. In general, symptom burden decreased and QoL improved during four cycles of treatment with nab-paclitaxel plus carboplatin. Positive changes from baseline were observed in several LCSS symptom scores, including cough, appetite, and pain. For the LCSS average total score, improvement from baseline peaked on cycle 2 day 1 and remained stable throughout the rest of the induction phase (Figure 1A). A similar trend was noted for the average symptom burden index (Figure 1B). For the lung cancer symptom score that rated the severity of disease-specific symptoms, improvements from baseline were observed during each of the four cycles of nab-paclitaxel plus carboplatin treatment (Figure 1C). The changes in global 
Table I Selected baseline characteristics

\begin{tabular}{|c|c|c|c|}
\hline Characteristic & $\begin{array}{l}\text { Responders } \\
(n=124)\end{array}$ & $\begin{array}{l}\text { Nonresponders } \\
(n=122)\end{array}$ & $\begin{array}{l}\text { Overall } \\
(N=246)\end{array}$ \\
\hline Age, median years (min-max) & $68(43-89)$ & $67(43-84)$ & $68(43-89)$ \\
\hline$\geq 70, \mathrm{n}(\%)$ & $55(44)$ & $46(38)$ & $10 I(4 I)$ \\
\hline$\geq 75, \mathrm{n}(\%)$ & $30(24)$ & $26(2 I)$ & $56(23)$ \\
\hline \multicolumn{4}{|l|}{ Sex, n (\%) } \\
\hline Male & $70(56)$ & $90(74)$ & $160(65)$ \\
\hline Female & $54(44)$ & $32(26)$ & $86(35)$ \\
\hline \multicolumn{4}{|l|}{ Race, n (\%) } \\
\hline White & $112(90)$ & 107 (88) & $219(89)$ \\
\hline Black or African American & $10(8)$ & $15(12)$ & $25(10)$ \\
\hline Other & $I(I)$ & $0(0)$ & $I(<1)$ \\
\hline \multicolumn{4}{|l|}{ ECOG PS, n (\%) } \\
\hline 0 & $39(31)$ & $38(3 I)$ & $77(3 \mathrm{I})$ \\
\hline I & $85(69)$ & $81(66)$ & $166(67)$ \\
\hline 2 & $0(0)$ & $3(3)$ & $3(1)$ \\
\hline
\end{tabular}

Abbreviation: ECOG PS, Eastern Cooperative Oncology Group performance status.

score remained generally stable with respect to baseline scores throughout the induction phase, as did the changes in the 3-item index scores (Figure 2A and B). Overall, 46\% of patients achieved a clinically meaningful improvement ( $\geq 10 \mathrm{~mm}$ ) from baseline in the composite score of pulmonary symptoms during the induction phase. Clinically meaningful improvements in the individual items of cough, shortness of breath, and hemoptysis were also reported in 58\%, 49\%, and $16 \%$ of patients, respectively.

\section{EQ-5D-5L}

Two-hundred and six patients who were lesion-responseevaluable with available QoL data from baseline and $\geq 1$ postbaseline visit were also included in the EQ-5D-5L analysis. The majority of patients experienced stability or improvement from baseline in individual EQ-5D-5L items, including self-care (91\%), mobility (88\%), anxiety/depression $(88 \%)$, pain/discomfort $(85 \%)$, and usual activities $(83 \%)$ (Table 2$)$. In patients reporting problems at baseline, complete resolution from baseline at least once during four cycles of treatment was reported in $30 \%$ to $50 \%$ of patients in individual EQ-5D-5L dimensions.

\section{LCSS and EQ-5D-5L by lesion response}

Overall, of lesion-evaluable patients who completed baseline and $\geq 1$ postbaseline QoL assessment, 110 were responders (CR/PR), and 96 were nonresponders. Responders had higher QoL scores compared with the overall population and nonresponders. LCSS average total score, average symptom burden index, and lung cancer symptom scores were improved from baseline in responders and were generally stable with respect to baseline in nonresponders (Figure $1 \mathrm{~A}-\mathrm{C}$ ). Overall, $56 \%$ of responders and $33 \%$ of nonresponders achieved a clinically meaningful improvement in the composite score of pulmonary symptoms.

Across all EQ-5D-5L dimensions, stabilization or improvements in QoL scores were more pronounced in responders vs nonresponders and vs the overall population (Table 2). The percentage of responders reporting complete resolution at least once was nearly double that of nonresponders in the individual dimensions of usual activities (39\% vs $21 \%$ ), pain/discomfort (44\% vs $27 \%$ ), and anxiety/ depression ( $59 \%$ vs $31 \%$ ).

\section{Discussion}

These are the first published data of QoL outcomes with $n a b$-paclitaxel plus carboplatin treatment in patients with advanced NSCLC. In this interim analysis of the Phase III ABOUND.sqm trial, treatment with four cycles of first-line $n a b$-paclitaxel plus carboplatin resulted in maintenance of or improvement in QoL in patients with advanced squamous NSCLC. Clinically meaningful improvements from baseline were observed in composite LCSS lung cancer pulmonary symptoms in $46 \%$ of patients. In addition, several EQ5D-5L components stabilized or improved in the majority of patients, and approximately one third of patients reported complete resolution of a problem reported at baseline at least once during four cycles of nab-paclitaxel plus carboplatin. Improvement in QoL was more pronounced in responders compared with the overall population and nonresponders.

$n a b$-Paclitaxel plus carboplatin is a recommended regimen for the first-line treatment of patients with both squamous 
A

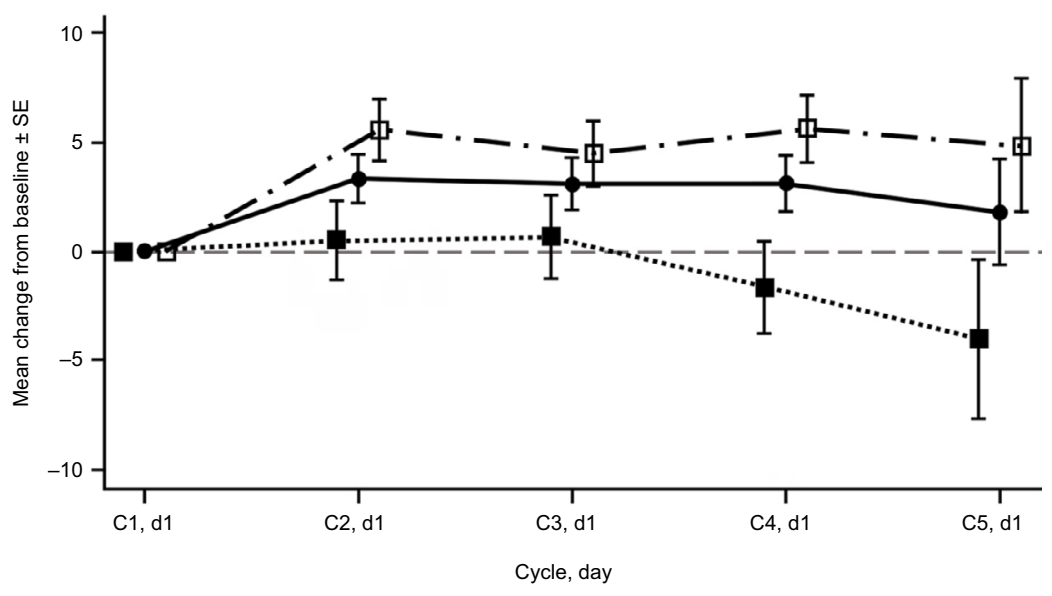

$\begin{array}{lccccc}\text {-- Overall } & 206 & 186 & 160 & 143 & 58 \\ \text { Ð. Responder } & 110 & 103 & 100 & 94 & 38 \\ \text { \#- Nenresponder } & 96 & 83 & 60 & 49 & 20\end{array}$

B

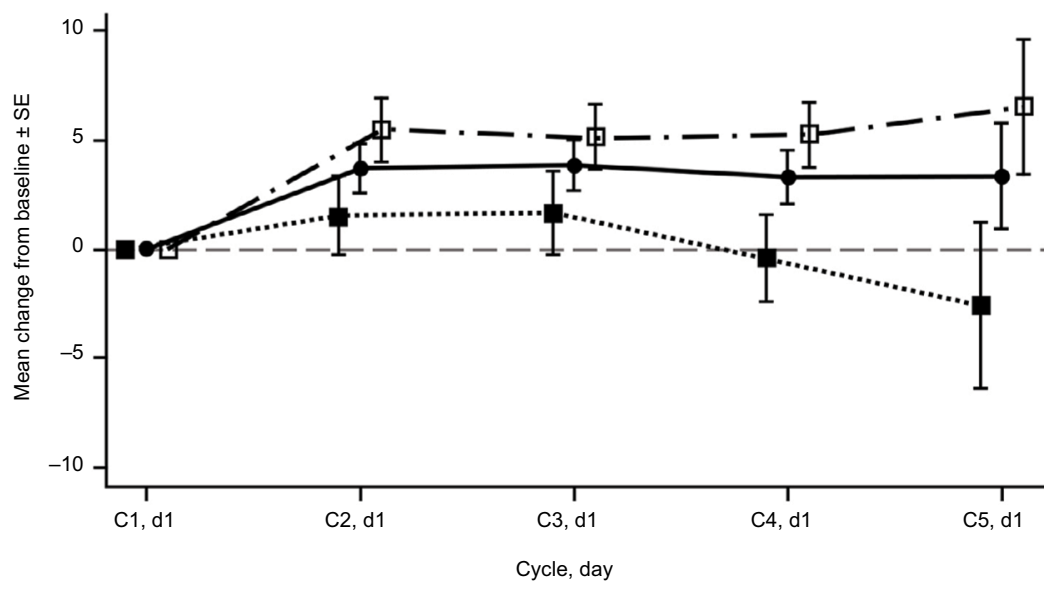

$\begin{array}{lccccc}\text { - O Overall } & 206 & 186 & 160 & 143 & 58 \\ \text { Ð. Responder } & 110 & 103 & 100 & 94 & 38 \\ \text {-E. Nonresponder } & 96 & 83 & 60 & 49 & 20\end{array}$

C

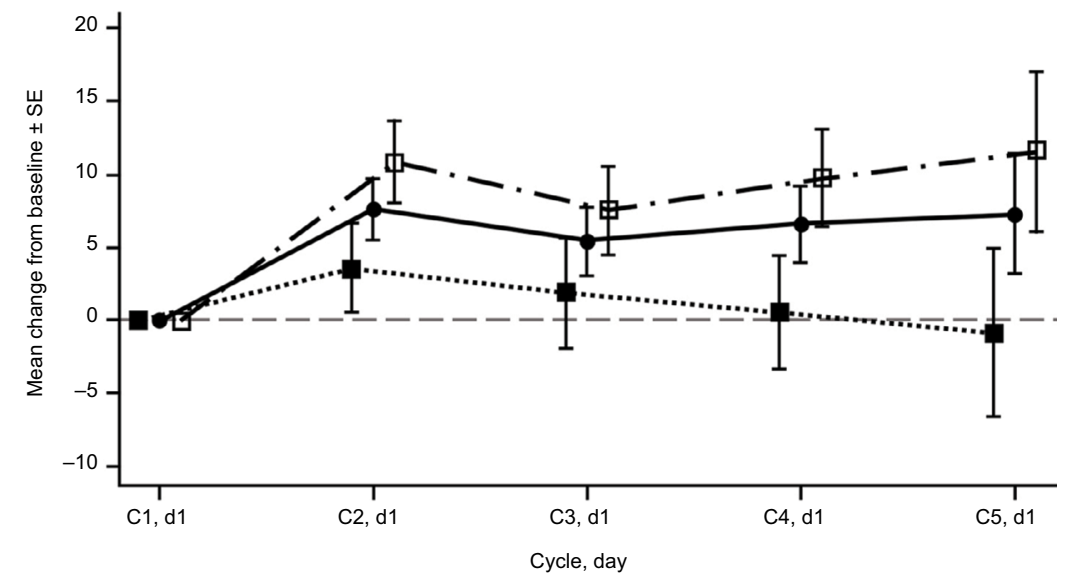

$\begin{array}{lccccc}\text { ๑-Overall } & 206 & 186 & 160 & 143 & 58 \\ \text { Ð. Responder } & 110 & 103 & 100 & 94 & 38 \\ \text {.-E. Nonresponder } & 96 & 83 & 60 & 49 & 20\end{array}$

Figure I Lung Cancer Symptom Scale average total (A), average symptom burden index (B), and lung cancer symptom (C) scores. Abbreviations: $\mathrm{C}$, cycle; $d$, day. 
A

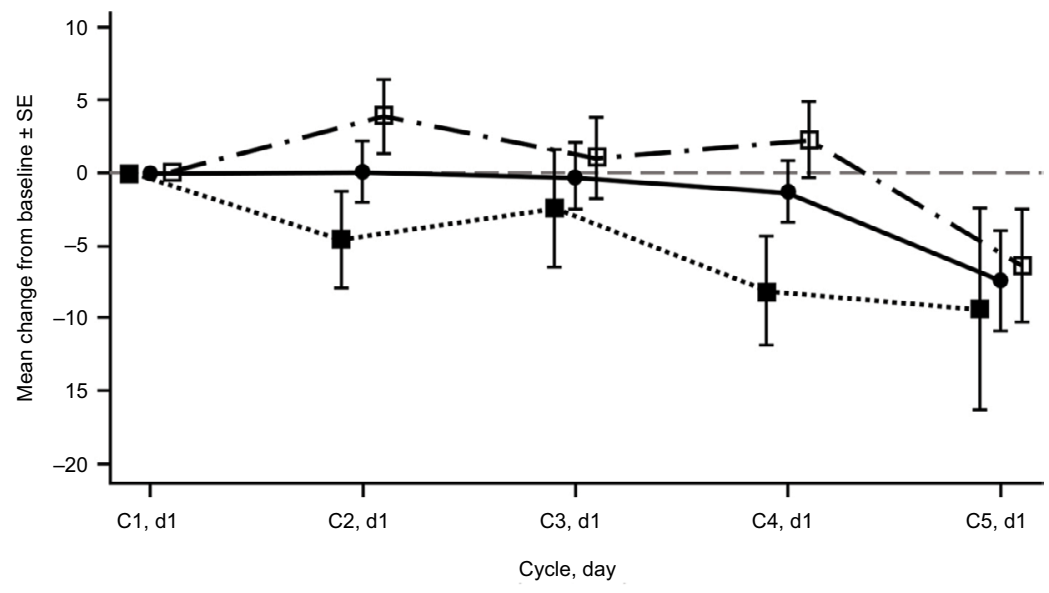

\begin{tabular}{|c|c|c|c|c|c|}
\hline$\rightarrow$ Overall & 206 & 186 & 160 & 143 & 58 \\
\hline$\bigoplus \cdot$ Responder & 110 & 103 & 100 & 94 & 8 \\
\hline - $=$ Nonresponder & 96 & 83 & 60 & 49 & 0 \\
\hline
\end{tabular}

B
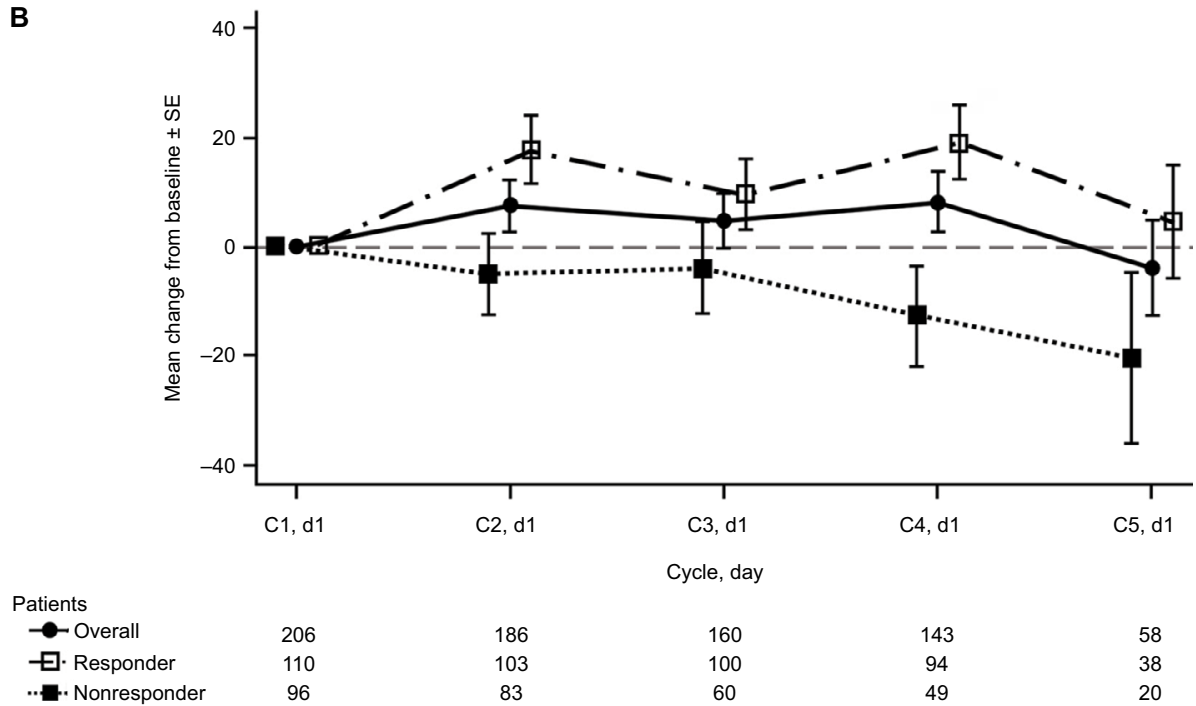

$\begin{array}{ll}206 & 186 \\ 110 & 103 \\ 96 & 83\end{array}$

160
100

100
60

Figure 2 Lung Cancer Symptom Scale global (A) and 3-item index (B) scores.

Abbreviations: C, cycle; d, day.

Table 2 EQ-5D-5L maintenance/improvement and complete resolution of problems in each dimension

\begin{tabular}{|c|c|c|c|c|c|c|}
\hline \multicolumn{7}{|l|}{ EQ-5D-5L } \\
\hline \multirow[t]{3}{*}{ Dimension } & \multirow{2}{*}{\multicolumn{3}{|c|}{$\begin{array}{l}\text { Maintenance/improvement } \\
\text { at least once during treatment, } n / N(\%)\end{array}$}} & \multirow{2}{*}{\multicolumn{3}{|c|}{$\begin{array}{l}\text { Complete resolution } \\
\text { at least once during treatment, } n / N(\%)^{a}\end{array}$}} \\
\hline & & & & & & \\
\hline & Responders & Nonresponders & Overall & Responders & Nonresponders & Overall \\
\hline Mobility & $104 / 110(95)$ & $78 / 96(8 I)$ & 182/206 (88) & 19/52 (37) & $|7 / 5|(33)$ & $36 / 103(35)$ \\
\hline Self-care & $107 / 110(97)$ & $81 / 96(84)$ & I88/206 (9I) & I4/24 (58) & $10 / 24(42)$ & $24 / 48(50)$ \\
\hline Usual activities & $95 / 110(86)$ & $75 / 96(78)$ & 170/206 (83) & $27 / 70(39)$ & $13 / 63(2 \mid)$ & $40 / 133(30)$ \\
\hline Pain/discomfort & $100 / 110(91)$ & $76 / 96(79)$ & $176 / 206(85)$ & $36 / 82(44)$ & $17 / 63(27)$ & $53 / 145(37)$ \\
\hline Anxiety/depression & $106 / 110(96)$ & $75 / 96(78)$ & $181 / 206(88)$ & $39 / 66(59)$ & I5/49 (3I) & $54 / 115(47)$ \\
\hline
\end{tabular}

Note: an patients reporting problems at baseline.

Abbreviation: EQ-5D-5L, Euro-QoL-5 Dimensions-5 Levels.

and nonsquamous advanced NSCLC, based on results of the registrational Phase III trial vs paclitaxel plus carboplatin. 5,6,12 In the Phase III registrational trial, significant improvements in ORR were reported for $n a b$-paclitaxel plus carboplatin vs paclitaxel plus carboplatin for the intent-to-treat population, as well for the subset of patients with squamous histology. The regimen was well tolerated with significantly less grade $\geq 3$ neuropathy and arthralgia but more thrombocytopenia and 
anemia observed compared with paclitaxel plus carboplatin. ${ }^{13}$ Additionally, significant improvements in taxane-related symptoms, such as neuropathy and neuropathic pain, were reported with $n a b$-paclitaxel plus carboplatin compared with paclitaxel plus carboplatin, regardless of histology. ${ }^{14}$ The improvements in QoL reported during four cycles of $n a b-$ paclitaxel plus carboplatin treatment from the ABOUND. sqm study corroborate these findings and further expand the understanding of the overall clinical benefit of the $n a b$ paclitaxel plus carboplatin regimen in patients with advanced NSCLC. ${ }^{12,14,18}$

Given the substantial symptom distress (cough, pain, loss of appetite, and hemoptysis) associated with both lung cancer and its treatment, QoL data are becoming an important tool for chemotherapy decision making. ${ }^{19-23}$ The high tumor burden in many patients with advanced NSCLC can result in a negative impact on QoL and worsen disease-related symptoms. ${ }^{24,25}$ Patients with squamous histology represent nearly one third of all patients with NSCLC; thus, analyses of QoL are of great significance, as the location, size, and cavitating nature of many squamous NSCLC tumors may increase the symptomatic burden compared with other histologies. ${ }^{25-27}$ However, there remains a lack of prospective clinical trial data of the impact of chemotherapy on symptoms/QoL, particularly for platinum-doublet therapy in patient subsets with unmet needs, such as squamous NSCLC. The current analysis adds to the limited body of knowledge on QoL data in patients with squamous NSCLC treated with first-line platinum doublets, and indicates that four cycles of nabpaclitaxel plus carboplatin treatment maintain or improve QoL in this patient population.

In addition to symptoms, patient health status (i.e., mobility, anxiety/depression, and usual activities) can be impacted by disease and treatment. For example, in a cross-sectional study of 126 newly diagnosed patients with advanced NSCLC treated with docetaxel plus cisplatin, $38 \%$ reported depression at baseline. ${ }^{28}$ QoL significantly declined with treatment in these patients, relative to those who did not report depression at baseline. In addition, depression was associated with worse survival. Another study assessed QoL changes in patients with advanced NSCLC $(\mathrm{N}=39)$ and found significant declines from baseline in physical and social functioning, among other QoL areas, during treatment with platinumdoublet chemotherapy. ${ }^{29}$ In the current study evaluating $n a b$-paclitaxel plus carboplatin treatment, some health status issues (individual EQ-5D-5L dimensions of mobility, anxiety/ depression, usual activities, pain/discomfort, and self-care) were maintained or improved in the majority of patients, with $\approx 30 \%$ reporting complete resolution from baseline at least once during treatment.

Understanding the impact of response on QoL is also important, as tumor shrinkage associated with tumor response could alleviate symptoms that are related to tumor size. ${ }^{30,31} \mathrm{In}$ the current study, QoL improvements measured by both the LCSS and the EQ-5D-5L were more pronounced in patients responding (CR/PR) to $n a b$-paclitaxel plus carboplatin during the induction phase of the study vs those not responding. In line with these findings, in a retrospective analysis of patient-reported health-related QoL data from a large Phase III study in advanced NSCLC $(\mathrm{N}=488)$, patients with a $\mathrm{CR} / \mathrm{PR}$ or stable disease after treatment with pemetrexed or docetaxel demonstrated statistically significant mean maximum improvements from baseline in all LCSS items except for hemoptysis. ${ }^{30}$ In contrast, mean LCSS scores for each individual item worsened for patients with disease progression. Although the response data in this analysis are preliminary, they provide some insight on the clinical benefit of nab-paclitaxel plus carboplatin in patients with advanced squamous NSCLC.

EQ-5D and LCSS are validated tools for QoL measurements, yet they both have limitations that have been discussed at length elsewhere. ${ }^{15,16,32}$ Limitations of this analysis include QoL assessment only during the induction phase, the homogeneous patient subset with respect to race (mostly white), and the limited patient number in some cycles. In addition, differences in use of supportive care for the treatment of pain may have diluted the results of the EQ-5D-5L pain/ discomfort category. Further analyses including data from the maintenance setting are forthcoming and may help strengthen future QoL analyses from this study.

\section{Conclusion}

These results from the Phase III ABOUND.sqm trial demonstrate that four cycles of first-line $n a b$-paclitaxel plus carboplatin improved or maintained QoL in patients with advanced squamous NSCLC. In addition, patients with a tumor response (CR/PR) appeared to have better QoL outcomes than those without a response. These findings in conjunction with those reported from the Phase III registrational trial support $n a b$-paclitaxel plus carboplatin as a treatment choice for this difficult-to-treat patient population. Moreover, it appears that declining QoL observed in nonresponders may be related to symptoms of disease progression. Therefore, given the importance of response during induction therapy, the impact of four cycles of nab-paclitaxel combination treatment on QoL in the squamous population is promising. 


\section{Acknowledgments}

The authors thank Lipu Tan at Celgene for his programming work. Medical writing assistance was provided by Dena Jacob, PhD, MediTech Media, Ltd, funded by Celgene Corporation. The authors were fully responsible for all content and editorial decisions for this manuscript. This work was supported by Celgene Corporation.

\section{Disclosure}

MT: honoraria, AstraZeneca, Boehringer Ingelheim, BristolMyers Squibb, Celgene, Lilly Novartis, MSD, Roche. DRS: consulting/advisory role, Celgene; research funding, Celgene; travel, accommodations, expenses, Celgene. RMJ: nothing to disclose. MM: nothing to disclose. MAS: honoraria and speaker's bureau, Celgene. RDP: nothing to disclose. LG: nothing to disclose. JK: consulting/advisory role: Cardinal Health; speaker's bureau, Alexion, Celgene, Novartis. OJ: advisory or speaker, AstraZeneca, Boehringer Ingelheim, Bristol-Myers Squibb, Lilly, MSD, Pierre-Fabre, Pfizer, Roche. DM: advisory board, Celgene and BristolMyers Squibb, speaker's bureau, Genentech. DI: nothing to disclose. ESK: grant/research support, Celgene. HW: consultant/advisor and honoraria, AstraZeneca, BoehringerIngelheim, BristolMyersSquibb, Celgene, Genentech/Roche; Merck, Spectrum, Takeda; Speaker: BMS, Genentech/Roche. AK, NT, TJO: employment or leadership position and stock ownership, Celgene Corporation. CG: nothing to disclose.

\section{References}

1. Akin S, Can G, Aydiner A, Ozdilli K, Durna Z. Quality of life, symptom experience and distress of lung cancer patients undergoing chemotherapy. Eur J Oncol Nurs. 2010;14(5):400-409.

2. Larsson M, Ljung L, Johansson BB. Health-related quality of life in advanced non-small cell lung cancer: Correlates and comparisons to normative data. Eur J Cancer Care (Engl). 2012;21(5):642-649.

3. Hirsh V. Are the data on quality of life and patient reported outcomes from clinical trials of metastatic non-small-cell lung cancer important? World J Clin Oncol. 2013;4(4):82-84.

4. Iyer S, Roughley A, Rider A, Taylor-Stokes G. The symptom burden of non-small cell lung cancer in the USA: A real-world cross-sectional study. Support Care Cancer. 2014;22(1):181-187.

5. National Comprehensive Cancer Network Clinical Practice Guidelines in Oncology. Non-Small Cell Lung Cancer. V3. Fort Washington, PA, USA: National Comprehensive Cancer Network; 2017.

6. Novello S, Barlesi F, Califano R, et al. Metastatic non-small-cell lung cancer: ESMO clinical practice guidelines for diagnosis, treatment and follow-up. Ann Oncol. 2016;27 (Suppl 5):v1-V27.

7. Avelino CU, Cardoso RM, Aguiar SS, Silva MJ. Assessment of quality of life in patients with advanced non-small cell lung carcinoma treated with a combination of carboplatin and paclitaxel. J Bras Pneumol. 2015;41(2):133-142.

8. Geater SL, Xu CR, Zhou C, et al. Symptom and quality of life improvement in LUX-lung 6: an open-label phase III study of afatinib versus cisplatin/gemcitabine in Asian patients with EGFR mutation-positive advanced non-small-cell lung cancer. J Thorac Oncol. 2015;10(6):883-889.
9. Boye M, Wang X, Srimuninnimit V, et al. First-line pemetrexed plus cisplatin followed by gefitinib maintenance therapy versus gefitinib monotherapy in East Asian never-smoker patients with locally advanced or metastatic nonsquamous non-small-cell lung cancer: quality of life results from a randomized phase III trial. Clin Lung Cancer. 2016;17(2):150-160.

10. Yang JC, Hirsh V, Schuler M, et al. Symptom control and quality of life in LUX-lung 3: a phase III study of afatinib or cisplatin/pemetrexed in patients with advanced lung adenocarcinoma with EGFR mutations. J Clin Oncol. 2013;31(27):3342-3350.

11. Abraxane for injectable suspension (paclitaxel protein-bound particles for injectable suspension) (albumin-bound) [prescribing information]: Summit, NJ: Celgene Corporation; 2015.

12. Socinski MA, Bondarenko I, Karaseva NA, et al. Weekly nab-paclitaxel in combination with carboplatin versus solvent-based paclitaxel plus carboplatin as first-line therapy in patients with advanced non-small-cell lung cancer: final results of a phase III trial. J Clin Oncol. 2012;30(17):2055-2062.

13. Socinski MA, Langer CJ, Okamoto I, et al. Safety and efficacy of weekly $\mathrm{nab}^{\circledR}$-paclitaxel in combination with carboplatin as first-line therapy in elderly patients with advanced non-small-cell lung cancer. Ann Oncol. 2013;24(2):314-321.

14. Hirsh V, Okamoto I, Hon JK, et al. Patient-reported neuropathy and taxane-associated symptoms in a phase 3 trial of nab-paclitaxel plus carboplatin versus solvent-based paclitaxel plus carboplatin for advanced non-small-cell lung cancer. J Thorac Oncol. 2014;9(1):83-90.

15. Hollen PJ, Gralla RJ, Kris MG, et al. Measurement of quality of life in patients with lung cancer in multicenter trials of new therapies. Psychometric assessment of the Lung Cancer Symptom Scale. Cancer. 1994;73(8):2087-2098.

16. Herdman M, Gudex C, Lloyd A, et al. Development and preliminary testing of the new five-level version of EQ-5D (EQ-5D-5L). Qual Life Res. 2011;20(10):1727-1736.

17. euroqol.org [homepage on the Internet]. EuroQol. EQ-5D. EuroQol; 2016. Available from: www.euroqol.org. Accessed: August 31, 2017.

18. Braun DP, Gupta D, Staren ED. Quality of life assessment as a predictor of survival in non-small cell lung cancer. BMC Cancer. 2011;11:353.

19. Hollen PJ, Gralla RJ, Kris MG, Eberly SW, Cox C. Normative data and trends in quality of life from the Lung Cancer Symptom Scale (LCSS). Support Care Cancer. 1999;7(3):140-148.

20. Temel JS, Greer JA, Muzikansky A, et al. Early palliative care for patients with metastatic non-small-cell lung cancer. NEngl J Med. 2010; 363(8):733-742.

21. Temel JS, Pirl WF, Lynch TJ. Comprehensive symptom management in patients with advanced-stage non-small-cell lung cancer. Clin Lung Cancer. 2006;7(4):241-249.

22. Smith EL, Hann DM, Ahles TA, et al. Dyspnea, anxiety, body consciousness, and quality of life in patients with lung cancer. J Pain Symptom Manage. 2001;21(4):323-329.

23. US Department of Health and Human Services, US Food and Drug Administration, Center for Drug Evaluation and Research, Center for Biologics Evaluation and Research. Guidance for industry: clinical trial endpoints for the approval of cancer drugs and biologics. FDA; 2007. Available from: http://www.fda.gov/downloads/Drugs/.../Guidances/ ucm071590.pdf. Accessed: August 31, 2017.

24. Geiger C, Chen Z, Zhang C, et al. Investigating the correlation between disease burden and symptoms in patients with advanced stage lung cancer. J Clin Oncol. 2015;33 Suppl: abstract e19057.

25. Nichols L, Saunders R, Knollmann FD. Causes of death of patients with lung cancer. Arch Pathol Lab Med. 2012;136(12):1552-1557.

26. Drilon A, Rekhtman N, Ladanyi M, Paik P. Squamous-cell carcinomas of the lung: emerging biology, controversies, and the promise of targeted therapy. Lancet Oncol. 2012;13(10):e418-e426.

27. Scagliotti GV, Novello S, Rapetti S, Papotti M. Current state-of-the-art therapy for advanced squamous cell lung cancer. Am Soc Clin Oncol Educ Book. 2013:354-358.

28. Chen J, Li W, Cui L, et al. Chemotherapeutic response and prognosis among lung cancer patients with and without depression. J Cancer. 2015;6(11):1121-1129. 
29. Arraras JI, Hernandez B, Martinez M, et al. Quality of life in Spanish advanced non-small-cell lung cancer patients: determinants of global QL and survival analyses. Springerplus. 2016;5(1):836.

30. de Marinis F, Pereira JR, Fossella F, et al. Lung Cancer Symptom Scale outcomes in relation to standard efficacy measures: an analysis of the phase III study of pemetrexed versus docetaxel in advanced non-small cell lung cancer. J Thorac Oncol. 2008;3(1):30-36.
31. Wu YL, Fukuoka M, Mok TS, et al. Tumor response and health-related quality of life in clinically selected patients from asia with advanced non-small-cell lung cancer treated with first-line gefitinib: post hoc analyses from the IPASS study. Lung Cancer. 2013;81(2):280-287.

32. Oppe M, Devlin NJ, van Hout B, Krabbe PF, de Charro F. A program of methodological research to arrive at the new international EQ-5D-5L valuation protocol. Value Health. 2014;17(4):445-453. 


\section{Supplementary material}

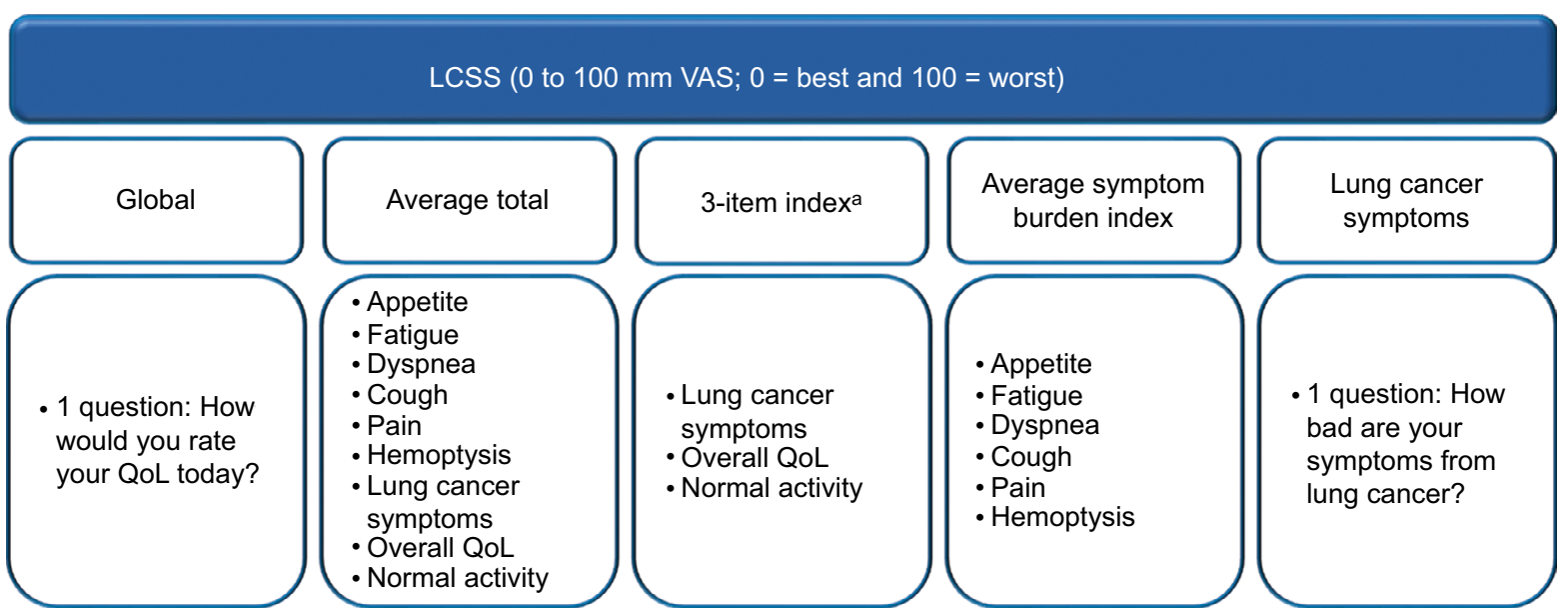

Figure SI Components of the LCSS used in this analysis.

Note: ${ }^{\text {a }}$ The 3-item index is a sum of the listed items and is scaled from 0 to $300 \mathrm{~mm}$.

Abbreviations: LCSC, Lung Cancer Symptom Scale, QoL, quality of life; VAS, visual analog scale.

\section{Publish your work in this journal}

Lung Cancer: Targets and Therapy is an international, peer-reviewed, open access journal focusing on lung cancer research, identification of therapeutic targets and the optimal use of preventative and integrated treatment interventions to achieve improved outcomes, enhanced survival and quality of life for the cancer patient. Specific topics covered in the journal include: Epidemiology, detection and screening; Cellular research and biomarkers; Identification of biotargets and agents with novel

mechanisms of action; Optimal clinical use of existing anticancer agents, including combination therapies; Radiation and surgery; Palliative care; Patient adherence, quality of life, satisfaction; Health economic evaluations. The manuscript management system is completely online and includes a very quick and fair peer-review system. Visit http://www.dovepress.com/testimonials.php to read real quotes from Submit your manuscript here: https://www.dovepress.com/lung-cancer-targets--therapy-journal 